\title{
Battery-less Power Conditioning System using Mechanical Fly Wheel
}

\author{
G. Ezhilarasan, Akhil Sundaram, Ajil Ahamed, Muhammed Shanu
}

\begin{abstract}
Considering the abundant sunlight so as the insolation available over many months in the Indian sub-continent, renewable energy can be easily harvested using solar photovoltaic array to supplement the grid power. This work proposes such an arrangement through a battery less UPS system. The need for battery less UPS system arises since batteries used in the conventional UPS system have less life time and a major concern of environmental pollution. Considering a premises/ organization where there is a power back up facility like a diesel generator, the role of batteries in the UPS system is limited and used for only few seconds between the mains power failure and the turning on of generator. Hence for such short term power requirements, a Kinetic Energy based medium for storage such as fly-wheel based energy storage can be effectively utilized instead of the electrochemical batteries. Hence the combination of solar PV based power generation along with a battery less online power conditioning system to supply a critical load is the proposed in this scheme.
\end{abstract}

Keywords: Battery less converter, Energy Storage, Flywheel Energy Storage, Resonant Converter, Renewable Energy.

\section{INTRODUCTION}

$\mathbf{N}_{\text {eed for micro grid reliable power supplies are the }}$ urgent need due to the world getting sophisticated day by day. Dependency on computers and automation are the main reasons for the increased power requirements. In this scenario energy production through non-conventional sources and their storage has become a big task. While it is easier to store power produced by a photo voltaic system or wind power system through electro chemical batteries, the usage of the same has caused various environmental issues and the environmentalists around the globe are more concerned on the toxic substances which it contains. Since batteries have less life time and they are very extensively used in domestic as well as industrial applications including transport being a major player, they have to be carefully recycled otherwise will result in environmental pollution[1].

Revised Manuscript Received on December 11, 2019

G. Ezhilarasan*, Professor, Department of Electrical and Electronics Engineering, Aarupadai Veedu Institute of Technology, Chennai, Tamil Nadu, India, ezhilarasan.eee@avit.ac.in

Akhil Sundaram, UG Student, Department of Electrical and Electronics Engineering, Aarupadai Veedu Institute of Technology, Chennai, Tamil Nadu, India, akhilsundaram@gmail.com .

Ajil Ahamed, UG Student, Department of Electrical and Electronics Engineering, Aarupadai Veedu Institute of Technology, Chennai, Tamil Nadu, India, ajilahamed96@gmail.com.

Muhammed Shanu, UG Student, Department of Electrical and Electronics Engineering, Aarupadai Veedu Institute of Technology, Chennai, Tamil Nadu, India.

With the fast depletion of conventional energy fuels, energy production through sources of renewable energy that from sun (solar), wind power are those gaining momentum. On the other hand, the batteries are used for both hight circumstances and small circumstances power requirement by improve the reliability of the energy supply. One such application of short term power requirement where batteries are used is in Uninterrupted Power Supplies (UPS) connected to critical load where the batteries are needed till a diesel generator connected with the system to turn on and take over the load.

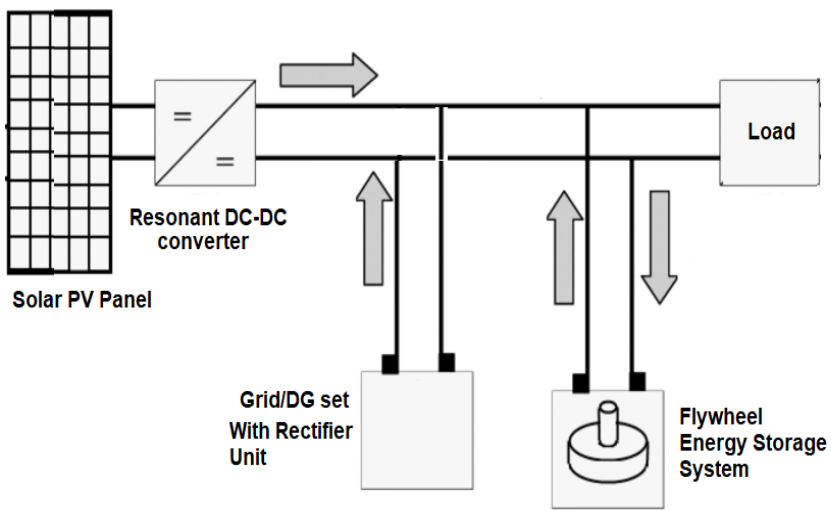

Fig. 1. Schematic representation of Flywheel Energy Storage System

This work proposes to realize a battery less UPS system using the concept of flywheel based energy storage system Fig 1. Here a mechanical flywheel which stores kinetic energy in it acts similar to the battery in providing short term energy requirement to the connected load during the power outages to improve the reliability of the proposed system.

The flywheel as a kinetic energy storage system is in existence and known to be a form of energy storage [2,3]. Also flywheel based energy storage system was preferred in transportation known as Gyro-bus, in 1950s [4]. Though the technology of flywheel based energy conditioning has already grown to a certain stage they were not preferred in power conditioning.

Mechanical flywheels can handle high energy, as well as high power and kinetic energy density [5], just to be compared with their conventional counterparts used for storing similar energy like transport, military, astro-space so on and so forth.[6,7]. The large capacity for storing energy of more than five hundred mega Joules, the mechanical flywheels has now become an important component of energy storage [8]. When compared with the electrochemical batteries, flywheels has more life time, they do not produce any extreme gases or pollution to the environment, the 
electrochemical batteries also have less life time and limited power range[9]. So now the flywheel based energy storage system are preferred for online based UPS systems connected to the critical loads [10-12]. The system is so proposed that it is normally independent of the grid since a photovoltaic system will be used for power generation in order to improve the reliability, a stand by generator and electrical grid will also be used. Thus the combination of solar power and flywheel make this work purely environment friendly due to absence of batteries and a fore runner for the society to go in for production and utilization of green energy [13-14].

The working of the system is simply explained as follows: the photo voltaic panels designed for this work feeds the power to the dc bus through a DC- converter acting as a charge controller to improve the reliability a DG set and an electrical mains supply also provided. When the sun is shining bright and good insolaion is present, the power from the panels is collected and is given to the DC motor connected to the flywheel system, the flywheel rotates and stores energy, at the same time the power is also fed to the load. In case of any slight fluctuations like transient conditions, the flywheel compensates the load with the energy stored in it, during that period the motor acts as the generator and the power saved in the flywheel is fed to the capacity of load. In case of low levels of insolation the load is then connected to the mains power supply, if the mains power supply is also absent, then the load will be connected to the DG set, thus the continuous operation of the load is ensured.

\section{PROPOSED MODEL}

\section{A. Flywheel}

A rotating flywheel stores mechanical energy device. It is a strong spin wheel called rotor that saved kinetic energy due to its rotation. In a FESS, the flywheel rotor is coupled directly with an electrical motor and an alternator, connected through a single shaft and fixed in a metallic base frame. The motor receives its electrical input and produces mechanical rotation of its shaft; the flywheel rotor which is connected with this shaft is also rotated and starts to store kinetic energy.

A part of the energy is also given to the alternator when there is associated to the same shaft of the device, when fixed firmly with the rotating flywheel. Hence, the energy in kinetic form which is generated by the machine acting as motor is now used to run the alternator and a part is now the kinetic energy in the rotating flywheel. Whenever there are transient conditions like sudden load variations, the flywheel absorbs such energy variations thereby providing a steady power output. When the power input to the motor is disrupted for little longer duration, then the stored kinetic energy using the flywheel rotor is changed into the electrical energy using the alternator and is fed to the load till an alternative source is connected or energy which is stored in the flywheel is dissipated.

Based on rotating speed as well as the inertia due to the weight of rotating flywheel, the specified value of kinetic energy is gained which then stored in the rotor as defined by, [14]

$$
E=\frac{I \omega^{2}}{2}
$$

Here, $\mathrm{E}$ is stored energy in kinetic form, I mom. of inertia (MOI), and speed $\omega$.

The MOI for any shape, mass, is given by,

$$
I=\frac{r^{2} m}{2}
$$

\section{Where}

$\mathrm{r}$ - radius and $\mathrm{m}$ - mass of the rotor.

$$
m=\rho V
$$

(3)

Where V - volume of flywheel rotor, $\rho$ - density of the flywheel material.

The max. energy density w.r.t volume and mass is given by,

$$
E=m \frac{k \sigma}{\rho}
$$

(4)

Where K- shape factor (1), $\sigma$-maximum stress (414 MPa) and $\rho$ - density $(7.8 \mathrm{~g} / \mathrm{cm} 3)$. The designed parameters are consolidated in Table 1 .

Table:I. Flywheel Parameters

\begin{tabular}{|l|c|c|}
\hline Parameters & Formulae & Specification \\
\hline Mass $(\mathrm{m})$ & $(\mathrm{k} \sigma / \rho) / \mathrm{E}$ & $3 \mathrm{~kg}$ \\
\hline Radius $(\mathrm{r})$ & $\pi \mathrm{r} 2 \mathrm{~h}$ & $0.25 \mathrm{~m}$ dia \\
\hline Inertia $(\mathrm{I})$ & $\mathrm{r} 2 \mathrm{~m} / 2$ & $13 \mathrm{~g} . \mathrm{m} 2$ \\
\hline Energy $(\mathrm{E})$ & $(\mathrm{mk} \sigma) / \rho$ & $2.2 \mathrm{~kJ}$ \\
\hline
\end{tabular}

The analysis of any model of specific structured load predicts the stresses, strains, displacements occurred during a specified time of functioning of that system. When a body is stretched beyond this will lead to complete failure of the

$$
\begin{aligned}
& v_{v_{L}}(t)=V_{S}-V_{O} \\
& i_{L_{L}}(t)=i_{L}\left(t_{0}\right)-\frac{V_{O}-V_{S}}{L_{1}} t \\
& i_{D_{Q}}(t)=i_{L}(t) \\
& i_{L_{y}}(t)=0 \\
& v_{C_{r}}(t)=V_{O}
\end{aligned}
$$

material. Hence for the above designed flywheel, a proper choice of material between steel and cast iron is done by comparing the stress obtained through the stress analysis method in ANSYS software.

Taking the standard parameters for the materials steel and cast iron, the stress analysis is done. Cast iron is found to be more elastic than steel since the ultimate stress of cast iron is less than steel [15] and are given in table II. 
Table: II Standard Material Parameters

\begin{tabular}{|c|c|c|}
\hline Parameter & Cast iron & Steel \\
\hline Density & $7200 \mathrm{kgm} 3$ & $7850 \mathrm{kgm} 3$ \\
\hline Poisons ratio & 0.28 & 0.3 \\
\hline Young's modulus & $1.1 * 105 \mathrm{MPa}$ & $2 * 105 \mathrm{MPa}$ \\
\hline Ultimate stress & $240 \mathrm{MPa}$ & $460 \mathrm{MPa}$ \\
\hline
\end{tabular}

\section{RESONANT DC- CONVERTER}

The auxiliary resonant circuit consists of main switch (S1), auxiliary semi conductor switch (S2), resonating capacitor $(\mathrm{Cr})$, resonating inductor $(\mathrm{Lr}), \mathrm{PN}$ junction diodes (D1 and D2), depicted in Fig. 2. The working of this circuit is in six intervals. Only one interval is discussed.

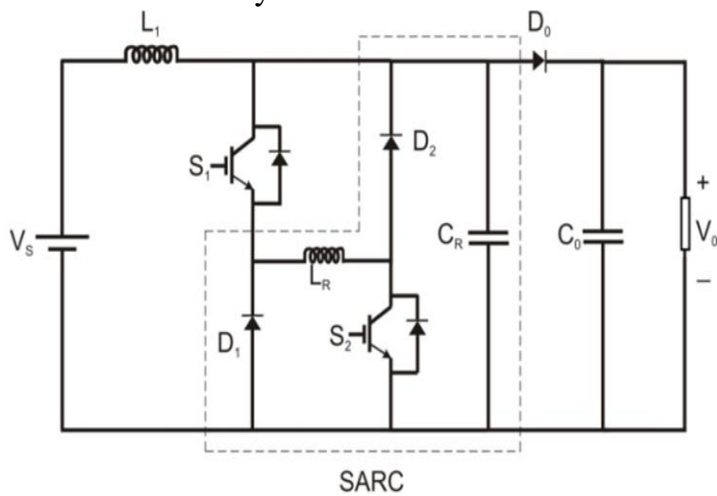

Fig. 2. Resonant Boost Converter

\section{A. Interval-1 ( $\mathbf{t 0} \leq \mathrm{t}<\mathrm{t} 1)$}

Switches in the circuit are in the OFF state initially, the current in the circuit shall not pass through $\mathrm{S} 1$ and $\mathrm{S} 2$, hence the accumulated energy in the inductor L1 is shifted to the load. During this period, the current in the main inductor reduces linearly. Hence, the current will cease to flow in the resonant inductor, as well as the resonant capacitor, which would have charged to the output voltage. After the switches $\mathrm{S} 1$ and S2 have been turned-ON, hence the first interval is over. These conditions are given as:

After switching on S1, S2, the current will flow in the resonating inductor. During which, the switches S1 and S2are turned- ON under ZCS condition. When the main as well as auxiliary switches implement ZCS, this converter will have lesser switching loss than the conventional hard switching converter

To satisfy the ZVS condition, the current in the resonant inductor shall exceed the main inductor during the next time interval. The rising time of the inductor current, the maximum resonant current during, the next interval, this is the resonant time corresponding to resonant inductor as well as capacitor, which is defined as quarter of the resonant period. The circuit in its open loop, the output is shown in fig 3 and Fig.4. Table III shows converter specifications

$$
\begin{aligned}
& t_{0 m}-t_{1}=\frac{L_{r}}{V_{O}} I_{\min } \\
& t_{3 m}-t_{2}=\frac{T_{r}}{4} \\
& \frac{L_{r}}{V_{O}} i_{\min }+\frac{T_{r}}{4}=0.1 D T \\
& \frac{V_{O}}{Z_{r}}>\Delta i_{L}
\end{aligned}
$$

Table: III. Converter Specifications

\begin{tabular}{|c|c|}
\hline Parameters & Ranges \\
\hline Input Voltage(V) & $200 \mathrm{~V}$ \\
\hline Switching Frequency (F) & $30 \mathrm{KHz}$ \\
\hline Main Inductor(L) & $560 \mathrm{mH}$ \\
\hline Resonant Inductor(Lr) & $40 \mu \mathrm{H}$ \\
\hline Resonant Capacitor $(\mathrm{Cr})$ & $20 \mathrm{nF}$ \\
\hline
\end{tabular}

\section{CLOSED LOOP CIRCUIT OF RESONANT CONVERTER}

The PI-controller using the operational are used here to control the voltage that is output for changes in the input as well as the corresponding ref. voltage. The Fig. 5 shows the pictorial diagram of the proposed boost converter in the closed-loop control mode.

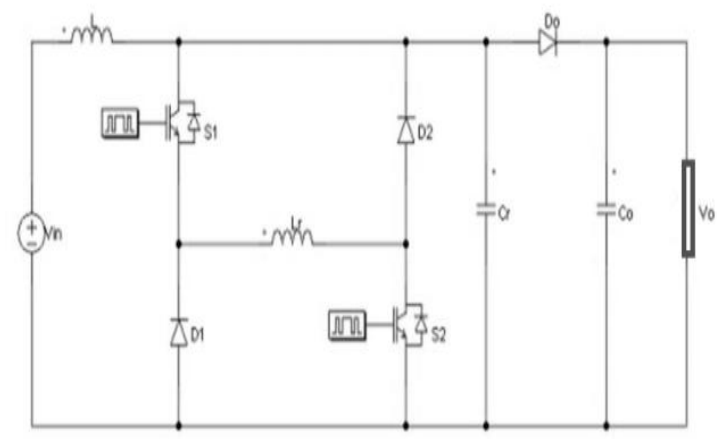

Fig. 3. The boost converter in open- loop circuit of in PSIM

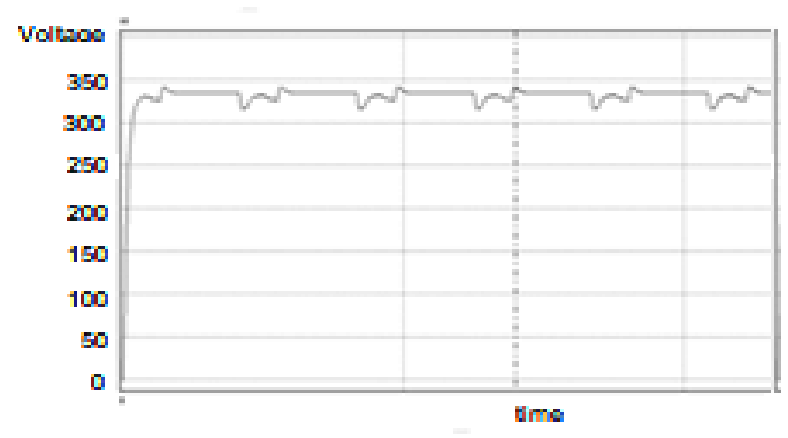

Fig. 4. The waveform of output voltage in open- loop.

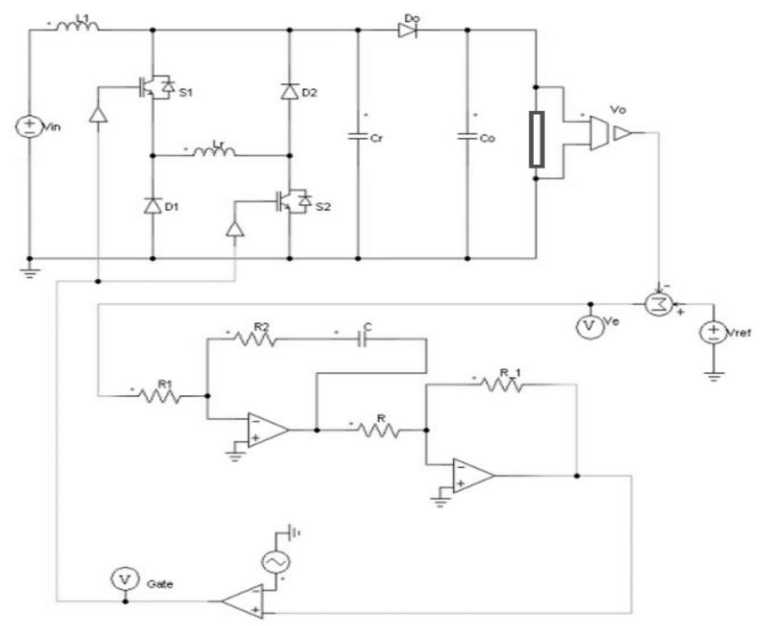

Fig. 5. Closed- loop circuit of the resonant boost converter 
From the output voltage shown in simulated waveform in the open circuit mode is as shown in Fig 5. The simulated waveform similarly of that of the output volt in closed loop as shown in Fig.6, it can be seen that in the closed-loop has greatly improved profile of the voltage, when compared with open

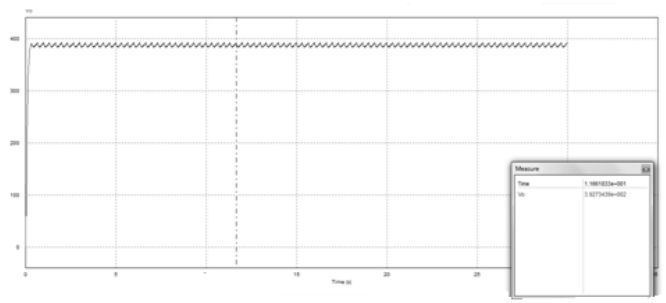

Fig. 6. Simulated waveform of output voltage in closedloop

This system was verified experimentally in the lab by using different electronic components. The basic- boost converter is connected as well as its working is verified. The basic-boost converter is then added with the SARC converter which is tested in the open circuit shown in Fig.3. The pi controller was assembled in the bread board and was tested initially both the circuits are combined in the bread board and verified the results that match in the same way with the practical results. The results are shown in table IV.

-loop.

Table: IV Comparison of Conventional Converter With Resonant Boost Converter

\begin{tabular}{|c|c|c|}
\hline \multicolumn{1}{|c}{ Resonant Boost Converter } \\
\hline Parameters & $\begin{array}{c}\text { Conventional } \\
\text { boost Converter }\end{array}$ & $\begin{array}{c}\text { Resonant boost } \\
\text { converter }\end{array}$ \\
\hline Output voltage & $398 \mathrm{~V}$ & $401 \mathrm{~V}$ \\
\hline Output current & $8 \mathrm{~A}$ & $8.4 \mathrm{~A}$ \\
\hline Efficiency & $93 \%$ & $95 \%$ \\
\hline
\end{tabular}

These two techniques of the switching were discussed and compared, found the proposed converter under this soft switching works better compared to the conventional hard switching.

\section{RESULTS AND DISCUSSION}

The full experimental setup of the flywheel based energy storage system consisting of a Brushless DC motor coupled to an alternator with flywheel fitted in between the motor-generator set as shown in Fig. 7. The resonant converter is shown in Fig 8. From the practical tests conducted it was found that the energy stored by the flywheel increased with the increase in speed. When the input to the prime mover connected to the flywheel is interrupted, the flywheel rotor was also able to maintain the energy stored in it up to 10 seconds with a constant speed of 1500 RPM with a microgrid of $1 \mathrm{~kW}$ load connected. To improve the reliability of the power supply to the load, if the interruption lasts even beyond run-time, the prime mover of the rotating flywheel based kinetic energy storage system is switched to back up sources like a diesel generator.
In order to validate the theoretical explanations and related calculations and to prove that the flywheel based energy storage system will act as a good power conditioner without using the electro chemical batteries, an experimental setup has to be made and it should be subjected various experimental procedure to obtain suitable observations has to be recorded. In this chapter the experimental setup of the flywheel based energy storage system is discussed in detail. The various modes of operation, waveforms are shown.

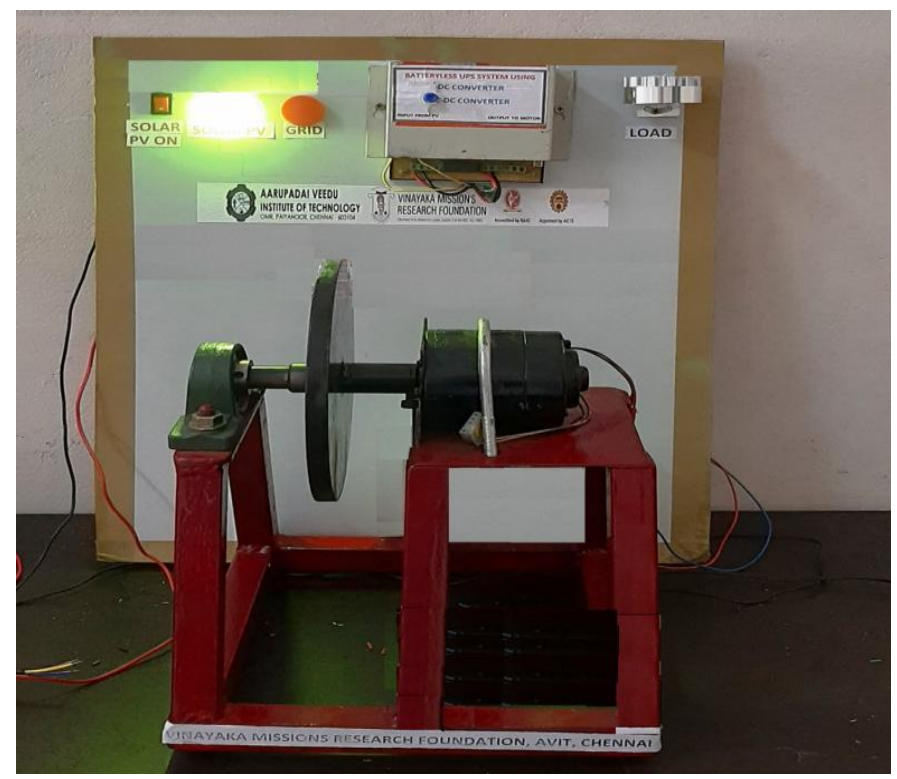

Fig. 7. View of the fabricated flywheel fitted with a motor

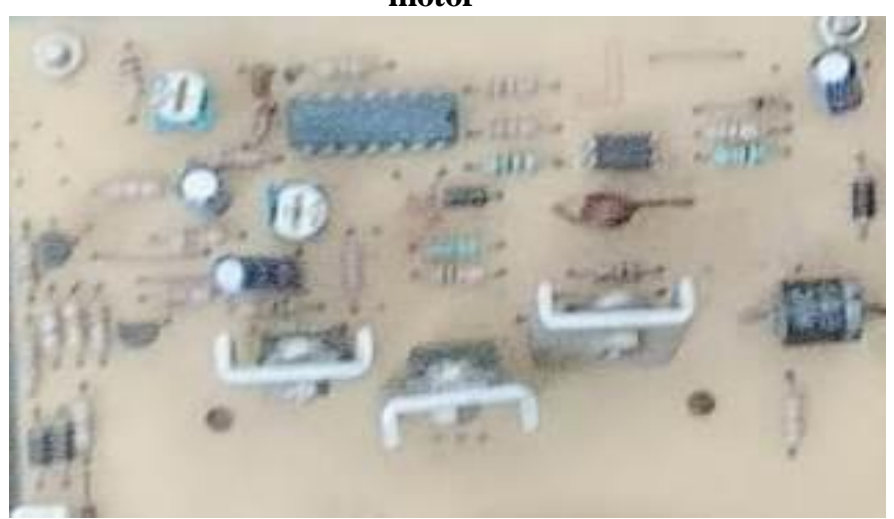

Fig. 8. Resonant boost converter circuit

\section{CONCLUSION}

This work is done on battery less power conditioning system using flywheel. The design and applications of the work and its comprehensive results are presented. This work provided a comparative analysis of traditional /conventional boost converter using the soft switching based auxiliary resonant converter. The boost converter which was used conventionally as well as the soft switching based resonant converter which was simulated. These results give the comparison as well as the efficiency improvement as discussed. The boost converter not only has high efficiency lesser voltage stress on its switches as well as the switching loss. So this converter is an important topology useful for medium power level. 
This improved quality of the soft switching boost converter is gaining popularity for applications that range from low as well as high power-levels based on their improved power quality in the input and the output terminals.

The hardware setup was assembled and was tested for its working in the laboratory. It was a satisfactory working, and the flywheel was able to retain energy and make the motor to act as a generator between the switching between the alternate supplies. Hence this project was successfully completed.

\section{REFERENCES}

1. M. Vijayalakshmi, R.Ramaprabha, G. Ezhilarasan, "Performance of BLDC Motor for Flywheel Energy Storage Applications, ” Indian Journal of Science and Technology, vol.9, no. 13, 2016, pp. 1-6.

2. Las Cruces, "Stand alone photovoltaic systems a hand book of design practices" SAND 87-7023, March 1995.

3. S.P. Thiruvadi, and S. Bhuvaneshwari, "Hybrid PV-Wind-Battery Based System For Household Applications Using DC-DC Converter," International Journal of MC Square Scientific Research, vol. 9, no. 1, 2017, pp.54-65.

4. J.B. Hans, Michael Sander, "Conceptual System Design of a 5 MWh/100 MW Superconducting Flywheel Energy Storage Plant for Power Utility Applications," IEEE Transaction on Applied Superconductivity, vol.7, no. 2, 1997, pp. 398-401

5. Yi Du, Liang Du, Bin Lu, Ronald Harley, and Thomas Habetler, “A Review of Identification and Monitoring Methods for Electric Loads in Commercial and Residential Buildings", Energy conversion congress and exposition, 2010, pp. 4527-4533.

6. Jinqi Li, Hui Zhang, Qian Wan, Jinhong Liu, Hongwei Zhang, "A Novel Charging Control for Flywheel Energy Storage System Based on BLDC Motor", Power and Energy Engineering conference, 2010, pp. 1-3.

7. Ezhilarasan Ganesan, Subhransu Sekhar Dash, "A New Approach in Modeling and Control of Distributed Energy Resources for Performance Optimization and Reliability Improvement in a Micro Grid," International review on modelling and simulation, vol. 8, no.1, 2015, pp.26-40, 2015

8. R.Arghandeh Jouneghani, M.Pipattanasomporn, S.Rahman, "Flywheel Energy Storage system for ride through application in facility microgrid", IEEE Transaction on Smart Grid, Vol.3, issue.4, pp. 1955-1962, Dec. 2012

9. G. Ezhilarasan, K.S. Jayasree, Isolated Buck-boost Converter for a Photovoltaic Energy Harvest System, International Journal of Applied Engineering Research, ISSN 0973-4562 vol. 10 no.4, 2015, pp.3775-3781

10. Seung-yong Hahn, Woo-seok Kim, Ji Hoon Kim, Chang-seop Koh, and Song-yop Hahn, "Low Speed FES with Induction Motor and Generator", IEEE Transaction on Applied Superconductivity, vol.12, no. 1, 2002, pp. 746-749.

11. Natural Resources Canada, "Photovoltaic project analysis", Clean energy project analysis: ret screen engineering \& cases textbook, ISBN: 0-662-35672-1 Catalogue no.: M39-99/2003

12. Sang-Hoon Park, So-Ri Park, Jae-Sung Yu, Yong-Chae Jung, Chung-Yuen Won, "Analysis and Design of a Soft-Switching Boos Converter With an HI-Bridge Auxiliary Resonant Circuit", IEEE Transaction on Power Electronics, vol.25, no. 8, 2010, pp. 2142-2149.

13. M. G. Villalva, J. R. Gazoli and E. R. Filho, "Comprehensive Approach to Modeling and Simulation of Photovoltaic Arrays", IEEE Transactions on Power Electronics, Vol.24, No.5, 2010,pp.1198-1208.

14. Avijit nayak, "Cost Economics of Solar kWh", energitica.

\section{AUTHORS PROFILE}

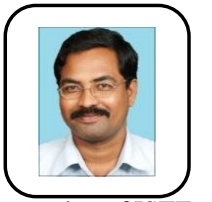

Dr. G. Ezhilarasan is currently working as a professor in EEE department of Aarupadai Veedu Institute of Technology. He obtained his B.E and M.E Degrees from College of Engineering Guindy, and Ph.D from SRM University. His area of interests is in power electronics, drives and renewable energy systems. He is currently a member of ISTE and IET.

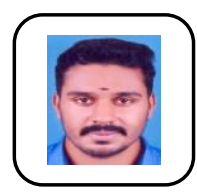

Akhil Sundaram graduated from Aarupadai Veedu Institute of Technology in 2019. He obtained his B.E in EEE and this paper is his final year project work.

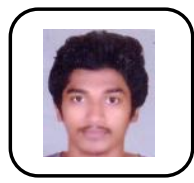

Ajil Ahamed graduated from Aarupadai Veedu Institute of Technology in 2019. He obtained his B.E in $\mathrm{EEE}$ and this paper is his final year project work.

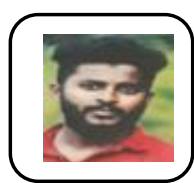

Mohammed Shanu graduated from Aarupadai Veedu Institute of Technology in 2019. He obtained his B.E in $\mathrm{EEE}$ and this paper is his final year project work. 